\title{
Analysis of roof membranes damaged by mechanical and climatic loads - pilot research
}

\author{
Jakub Čurpek ${ }^{1, *}$ and Jozef Oláh ${ }^{1}$ \\ ${ }^{1}$ Department of Building Structures, Faculty of Civil Engineering STU in Bratislava, Radlinského 11, \\ 81005 Bratislava, Slovakia
}

\begin{abstract}
Realization of roof construction has many hidden risks, especially in buildings with diverse architecture. There is a problem about cooperation of individual works (vertical and horizontal constructions) on roof in this type of architecture, during the process of realization. Purpose of this research is to reveal risks in form of the group of major source of defects by mechanical damages. The most often types of mechanical damages were chosen in this research, which then were applied on individual types of roof membranes. Response of this damage was found out during the test procedure of water pressure by special laboratory machines. Furthermore, samples of roof membranes were subjected to the Impact test, which was actually focused on damage by hailstone impact from the atmosphere. The final outcomes of the measurements show that the material composition of each roof membrane can influence their whole waterproofing after application of certain type of mechanical damage. In the Impact test, samples were suffered from impact of the hails. This test signified that the choice of base material of thermal insulation below the roof membrane plays an important role.
\end{abstract}

\section{Introduction}

Fundamental property of roof is the ability to resist negative atmospheric conditions during its whole lifetime. However, certain potential risks can cause damage of waterproof membrane within realization of a building. The dangerousness is hidden in the craftsmen's cooperation between to each other on a roof and adjacent construction of building. In the all phases of project it is necessary to have in mind that except of traditional designed loads (people, snow, etc.) also human behaviour factor is there. This special load is unpredictable and it cannot be specified in design process. Unfortunately, many workers on a site do not have only a marginal knowledge about function and manipulation of roof membranes and usually could inconsiderately damage them [1]. In doing so, one little damage on the membrane can cause really huge problems on the whole new building in the nearest future. Mostly, foremen try to obscure these problems in the effort to reach work time schedule and get a reward. In the many cases, building could not be able to undergo final inspection due to occurrence of waterproof failures. In addition to, special climatic conditions as hailstorm impact could be able to cause huge damage of membrane placed on some certain

\footnotetext{
* Corresponding author: jakub.curpek@gmail.com
} 
type of thermal insulation material. Physical properties, especially density and elasticity of underlay material can influence response of membrane under immediate impact of hails. The effort is to find the right way of explaining this influence between damages and whole waterproof functionality of roof.

\section{General example of damage}

Especially, it is requisite to give better attention during the realization of architecturally shaped objects where generally flat roofs prevail. This type of architecture with gradually changed floors generates a lot of problems with cooperation each step of work on the vertical and horizontal parts of building construction (roof/facade). In many cases, flat roof could provide good place for storing building material, site equipment or scaffold, Fig. 1c. General example of this type of building could provide recent restoration of roof on the building of Slovak University of Technology in Bratislava, Fig. 1a. Many damages of waterproof membranes have been done due to unprofessional and irrational working operations, Fig. 1b. These recent circumstances in practise make up the main reason why this pilot research has been done.

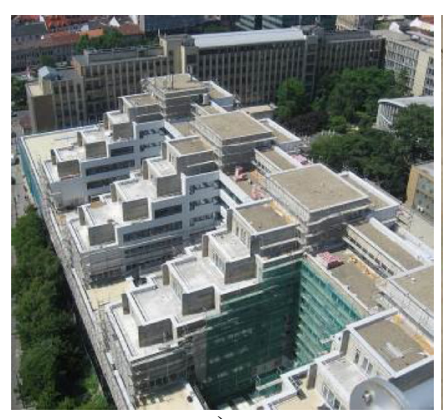

a.)

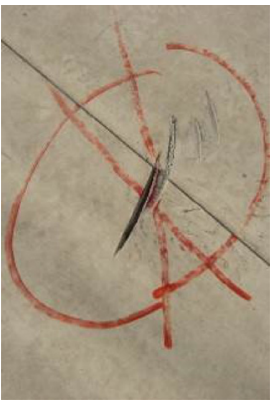

b.)

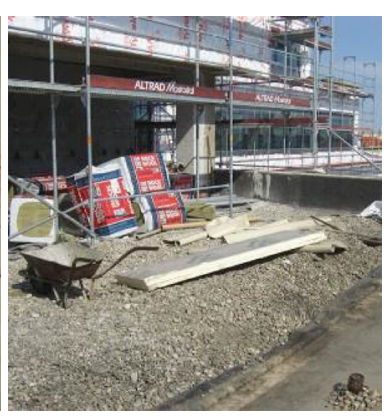

c.)

Fig. 1. The scene of roof restoration: a.) Faculty building of STU in Bratislava, b.) Mechanical damage PVC-P waterproof membrane, c.) Realization of horizontal and vertical construction of STU.

\section{Aims and methodology of the analysis}

Waterproof properties of roof membranes are determined mainly by each component part used in the whole material structure. The main goal of this research is investigation of dependency between material compositions of the foremost using membranes and mechanical and climatic damage. Analysis of this dependency function was found out by experimental measurements realized in the special laboratories. Two types of analysis have been done in this research: analysis of mechanical damage on membranes caused by human factor and its influence on membrane waterproofing, analysis of hailstorm impact on membranes subjected under laboratory temperature $20^{\circ} \mathrm{C}$ placed on different base material. Novel types of samples without any initial damages were used in the experimental measurements as well as samples taken from a site. Consequently, types of mechanical damage were chosen and implicated on membrane samples: $50 \mathrm{~mm}$ long knife cut (full and half of thick sample), nail perforation, screw perforation, Fig. 2.

Material of each used membrane samples was chosen as the most used material in a practise: modified asphalt styrene butadiene styrene (SBS) sheets (with fined-grained and coarse-grained strewing), plasticize polyvinyl chloride PVC-P foils (unreinforced, reinforced by polyester lining), ethylene propylene diene monomer (EPDM) foils (unreinforced, reinforced by polyester lining), thermoplastic polyolefin (TPO) foils. 


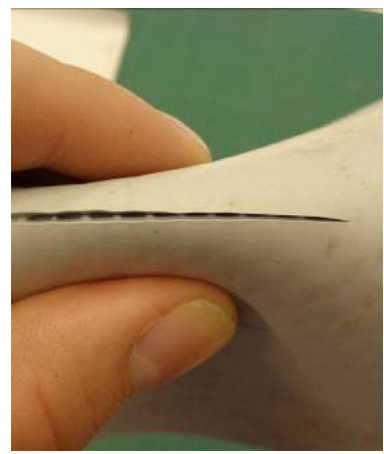

a.)

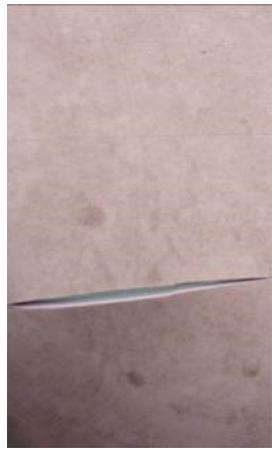

b.)

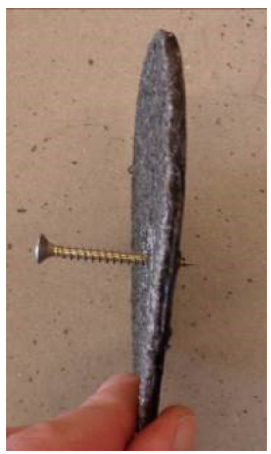

c.)

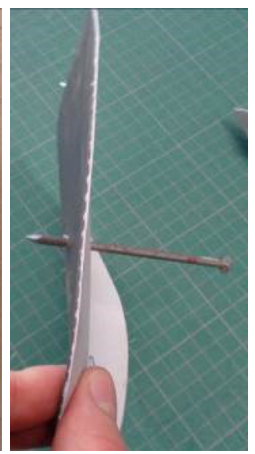

d.)

Fig. 2. Types of mechanical damage: a.) Half-cut knife, b.) Full-cut knife, c.) Nail perforation, d.) Screw perforation.

\subsection{Low water pressure testing procedure}

Tests were carried out by using EN 1928 method A to determinate watertight properties of investigated samples [2]. Procedure triple tester, Fig. 3a, provides measuring three samples at the same time under maximum water pressure $12 \mathrm{kPa}$ during 24 hour test period. Each sample was cut out for circle shape $(\phi 200 \mathrm{~mm})$ and then place upper side downwards into chamber, covered by filtrated paper and glass plate with a flange ring, Fig. 3b. Tightness of chamber is ensured by three wing screws situated around the ring. Filtration paper could provide instantaneously identification of water penetration through membrane. After checking the whole corrections of apparatus, opening of inlet valve provided flowing of coloured water into chamber and subsequently started to press on the samples until water column reached maximum value $1200 \mathrm{~mm}$. Samples were observed under the lower pressure during water pumping. If certain sample withstood process of filling up the water column then sample was leaved for observation during 24 hour.

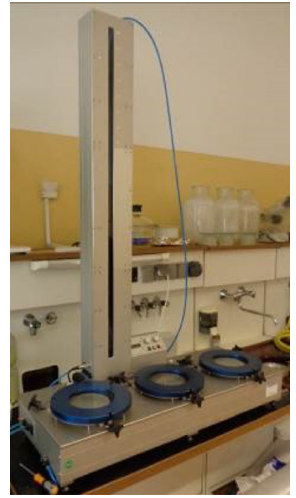

a.)

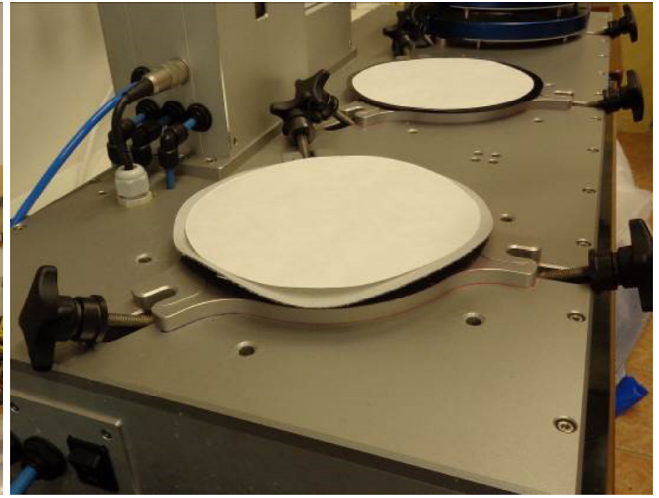

b.)

Fig. 3. Laboratory equipment for low-pressure water testing procedure: a.) Watertightness Tester WSP 3600 , b.) Putting samples into the chamber.

\subsection{High water pressure testing procedure}

This procedure could provide testing only one sample by one-time period in compliance with EN 1928 method B [2]. Samples were cut out circle shape $(\phi 130 \mathrm{~mm})$ and then place upper side downwards into apparatus and covered by a circular steel disk containing four 
slots, Fig. 4b. Cone-shaped covering was put on the disk and tightened by a clamp. Thereafter, opened inlet valve provided water flowing into the apparatus that immediately caused water pressure on the sample, Fig. 4a. Value of water pressure could be adjusted by throttle valve to maximum value $60 \mathrm{kPa}$.

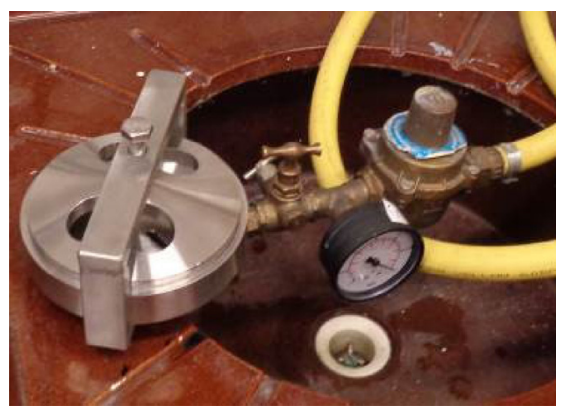

a.)

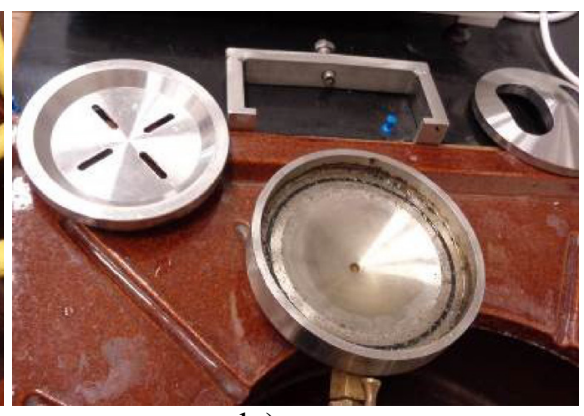

b.)

Fig. 4. Laboratory equipment for high-pressure water testing procedure: a.) Apparatus in process, b.) Each parts of apparatus.

\subsection{Impact test}

The principle of this test is about simulated impact of a certain weight on the membranes [3] with different underlay material: expanded polystyrene (EPS), mineral wool (MW), polyisocyanurate foam (PIR) and steel plate with $3 \mathrm{~mm}$ of thickness. This weight is represented by cylindrical steel drop mass $(500 \mathrm{~g})$ with a fixed puncturing spherical-shaped tool $(\phi 12.7 \mathrm{~mm})$, whole weight is attached on a release mechanism, Fig. 5b. The drop height was set up $2 \mathrm{~m}$ from the bottom of the puncturing tool to the upwards surface of the membrane. Each sample was burdened by ballast steel ring $(2 \mathrm{~kg})$ with inner diameter of $100 \mathrm{~mm}$, Fig. 5c. Investigation was not only focused on the membrane damage but also underlay material damage by weight impact. If it could not be possible visually to determinate character of damage, then sample was subsequently subjected under water pressure testing procedure.

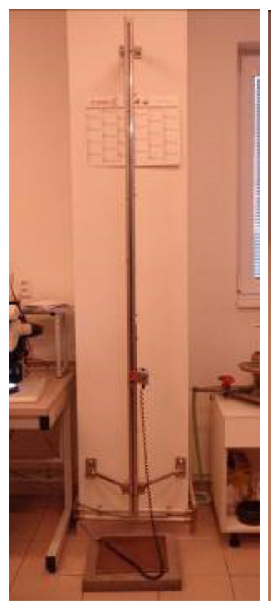

a.)

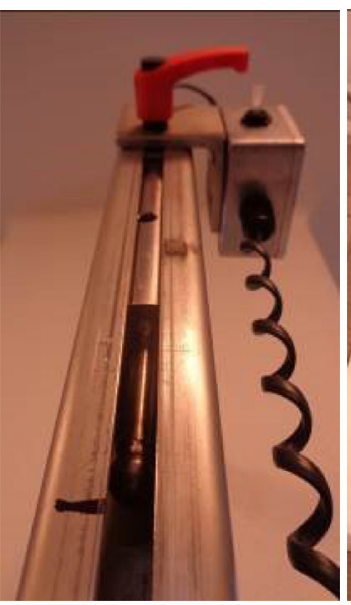

b.)

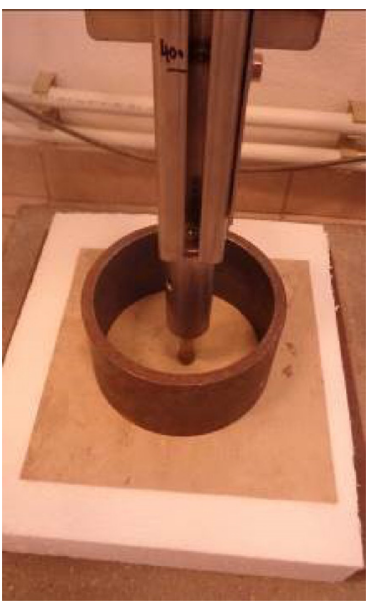

c.)

Fig. 5. Impact test equipment: a.) Whole apparatus, b.) Trigger with a setting device for variable drop, c.) Ballast ring on the sample. 


\section{Results of measurements}

\subsection{Results of water pressure testing procedure}

Every type of mechanical damage could influence waterproof functionality of membranes in a different point of view. Not all damages were applied on the each sample as well as not all samples were subjected under all testing procedures during this pilot research. The biggest distinctions can be observed on the PVC-P and EPDM foils which were tested as reinforced and unreinforced. Polyester lining could significantly influence waterproof function of membranes for the sake of it could work like conductor and provide transport of water to other side of a membrane. EPDM foils have great elastic properties so they could seal themselves around a puncturing tool. Both types of PVC-P foils damaged by $50 \mathrm{~mm}$ half knife cut could be able to withstand 24 hours under low water pressure. Half-cut damage cannot remarkably influence waterproof properties of membranes. Asphalt sheets were able to enclosure perforating tool by asphalt matter and resist under water pressure. Additionally, surface grain structure of asphalt sheets plays certain role in testing. However, these outcomes do not represent membrane performance during their whole life-time but only the very narrow time step.

Table 1. Results of low water pressure testing procedure.

\begin{tabular}{|l|c|c|c|}
\hline \multicolumn{1}{|c|}{ Sample } & $\begin{array}{c}\text { Mechanical } \\
\text { damage }\end{array}$ & $\begin{array}{c}\text { Water pressure } \\
{[\mathbf{k P a}]}\end{array}$ & Evaluation \\
\hline PVC-P, reinforced & $50 \mathrm{~mm}$ full cut & 1.10 & water penetration \\
\hline PVC-P, reinforced & screw perforation & 2.80 & water penetration \\
\hline PVC-P, unreinforced & $50 \mathrm{~mm}$ full cut & 12 & withstood 24 hours \\
\hline EPDM, unreinforced & $50 \mathrm{~mm}$ full cut & 12 & withstood 24 hours \\
\hline EPDM, unreinforced & nail perforation & 2.10 & water penetration \\
\hline EPDM, reinforced & $50 \mathrm{~mm}$ full cut & 5.15 & water penetration \\
\hline TPO & $50 \mathrm{~mm}$ full cut & 5.60 & water penetration \\
\hline TPO & nail perforation & 12 & $\begin{array}{c}\text { water penetration } \\
\text { (during 24 hours } \\
\text { observation) }\end{array}$ \\
\hline TPO & screw perforation & 5 & water penetration \\
\hline
\end{tabular}

Table 2. Results of high water pressure testing procedure.

\begin{tabular}{|l|c|c|c|}
\hline \multicolumn{1}{|c|}{ Sample } & $\begin{array}{c}\text { Mechanical } \\
\text { damage }\end{array}$ & $\begin{array}{c}\text { Water pressure } \\
{[\mathbf{k P a}]}\end{array}$ & Evaluation \\
\hline asphalt, fined-grained & none & 60 & water penetration \\
\hline asphalt, fined-grained & 50 mm half cut & 60 & withstood 24 hours \\
\hline asphalt, coarse-grained & no one & 60 & withstood 24 hours \\
\hline asphalt, coarse-grained & screw perforation & 60 & withstood 24 hours \\
\hline asphalt, coarse-grained & nail perforation & 60 & withstood 24 hours \\
\hline asphalt, coarse-grained & 50 mm half cut & 60 & withstood 24 hours \\
\hline EPDM, reinforced & none & 45 & water penetration \\
\hline EPDM, unreinforced & none & 60 & withstood 24 hours \\
\hline PVC-P, reinforced & none & 60 & withstood 24 hours \\
\hline
\end{tabular}




\subsection{Results of Impact test}

PVC-P samples (reinforced - taken directly from the site, reinforced - novel, unreinforced) were not considerably damaged, deformation of samples and underlay material was not so big except of underlay of steel plate where perforation of samples occurred in all causes.

Every sample of TPO foils was perforated on each thermal insulation material and little part of sample was ripped out and bored into insulation. In the case of underlay steel plate, little hole made up on a sample.

Unreinforced EPDM foils were not damaged on insulation, but their good elasticity caused damage of underlay insulation by sticking weight puncturing tool into it. The samples were damaged merely on the underlay steel plate.

Reinforced EPDM foils preformed like reinforced PVC-P foils. All samples had been elastically stretched and after that came back to base shape. No damage was occurring except of underlay steel plate where samples were perforated.

Asphalt sheets (coarse-grained) were entirely perforated ( $2 \mathrm{~m}$ drop high) and cracks occurred on the bottom side of samples ( $1.25 \mathrm{~m}$ and $1 \mathrm{~m}$ drop high) by puncturing tool on the EPS underlay. Samples placed on the MW and PIR were not damaged but on the steel plate they were.

\section{Conclusions}

Some certain type of mechanical damage (huge or little) is absolutely not accepted from waterproofing point of view. However, some unfortunate cases could happen (dropping sharp element, nail perforation by mounting some constructions, etc.) in the practise during realization or maintenance of roof. Purpose of this research is to find out dependency between mechanical damage and waterproof function of membranes and after that try to devise range of restoration works. Results showed that certain types of damaged membranes have better ability to withstand water pressure in comparison to each other. It is necessarily for engineers and architects to have knowledge about performance of roof membranes under certain working operations and climatic conditions as well. Workers on the site have to be instructed about the fragility of roof membranes before realization of a construction. Climatic conditions as hailstorm impact could create different performance of membranes placed on the different underlay material. Right selection of underlay is the most important especially for the regions with high dangerous rate of hail storm impact incidence. For the further research is necessary to investigate more membrane samples with combination to other type of mechanical damages and underlay materials.

This research project has been funded by the Ministry of Education, Science, Research and Sport of the Slovak Republic under the contracts VEGA 1/0710/13.

\section{References}

1. M. Novotný, I. Misar, S. Šutliak, Hydroizolace plochých střech. Poruchy střešních plášsti̊ (Nakladatel'stvo STU, Bratislava, 2014)

2. STN EN 192, Flexible sheets for waterproofing. Bitumen, plastic and rubber sheets for roof waterproofing. Determination of watertightness (2001)

3. STN EN 12691, Flexible sheets for waterproofing. Bitumen, plastic and rubber sheets for roof waterproofing. Determination of resistance to impact (2006) 